\title{
PENERAPAN METODE HOLT WINTER DAN SEASONAL ARIMA PADA PERAMALAN PERKEMBANGAN WISATAWAN MANCANEGARA YANG DATANG KE INDONESIA.
}

\author{
DILA MULYA, YUDIANTRI ASDI, FERRA YANUAR \\ Jurusan Matematika, \\ Fakultas Matematika dan Ilmu Pengetahuan Alam, Universitas Andalas, \\ Kampus UNAND Limau Manis Padang, Indonesia, \\ email : dila.mulya.2004@gmail.com
}

\begin{abstract}
Abstrak. Pada tugas akhir ini akan dirumuskan pemodelan peramalan perkembangan wisatawan mancanegara yang datang ke Indonesia dengan metode Holt Winter dan Seasonal ARIMA. Kemudian hasil peramalan perkembangan wisatawan dengan menggunakan kedua metode tersebut akan dibandingkan berdasarkan nilai Mean Squared Deviation (MSD), Mean Absolute Percentage Error (MAPE) serta Mean Absolute Deviation $(M A D)$. Berdasarkan hasil yang diperoleh, model terbaik untuk peramalan perkembangan wisatawan mancanegara yang datang ke Indonesia adalah model SARIMA $(0,1,1)(1,1,0)_{12}$, karena nilai MAPE, MAD dan MSD yang diperoleh lebih kecil daripada model Holt Winter.

Kata Kunci: Holt Winter, Seasonal Arima, Trend, Musiman
\end{abstract}

\section{Pendahuluan}

Pada era globalisasi saat ini, pariwisata menjadi salah satu sektor yang berkontribusi cukup besar pada setiap perkembangan serta pertumbuhan negara, termasuk Indonesia. Sektor pariwisata berperan sebagai salah satu sektor yang angka pertumbuhannya cukup signifikan, terutama terlihat dalam mendatangkan wisatawan mancanegara.

Data jumlah wisatawan mancanegara yang datang ke Indonesia merupakan data runtun waktu (time series). Data time series adalah data yang dikumpulkan, dicatat, atau diamati berdasarkan urutan waktu. Data time series tersebut dapat digunakan untuk peramalan. Ada empat pola data data dalam peramalan time series, yaitu pola musiman, siklis, trend, dan irregular.

Data perkembangan wisatawan mancanegara yang datang ke Indonesia mengandung pola musiman dan pola trend, sehingga metode Holt Winter dan Seasonal ARIMA dapat digunakan untuk meramalkan jumlah wisatawan di masa yang akan datang. Metode peramalan terbaik dilihat dengan cara membandingkan nilai error terkecil. Tingkat error peramalan didapat berdasarkan perhitungan menggunakan Mean Squared Deviation (MSD), Mean Absolute Deviation (MAD), dan Mean Absolute Percentage Error (MAPE) [7]. 


\section{Data dan Metode}

\subsection{Data}

Data yang digunakan dalam penelitian ini adalah data sekunder yang diperoleh dari situs resmi Kementerian Pariwisata (Kemenpar) yaitu data perkembangan wisatawan mancanegara yang datang ke Indonesia [4].

\subsection{Metode Holt Winter}

Data pada time series bisa dipengaruhi oleh pola trend, pola musiman, dan juga pola trend sekaligus pola musiman. Jika data dipengaruhi oleh pola trend dan pola musiman sekaligus maka metode yang digunakan adalah metode Holt Winter. Metode Holt-Winter didasarkan pada tiga persamaan pemulusan, yakni persamaan pemulusan keseluruhan, pemulusan trend, dan persamaan pemulusan musiman.

Persamaan yang digunakan dalam model multiplikatif Holt Winter, yaitu:

1. Pemulusan eksponensial data asli

$$
L_{t}=\alpha \frac{Y_{t}}{S_{t-s}}+(1-\alpha)\left(L_{t-1}+T_{t-1}\right)
$$

2. Pemulusan pola trend

$$
T_{t}=\beta\left(L_{t}-L_{t-1}\right)+(1-\beta) T_{t-1}
$$

3. Pemulusan pola musiman

$$
S_{t}=\gamma \frac{Y_{t}}{L_{t}}+(1-\gamma) S_{t-s}
$$

4. Ramalan p periode ke depan

$$
\hat{Y}_{t+p}=\left(L_{t}+p T_{t}\right) S_{t-s+p}
$$

dimana

$L_{t}$ : nilai pemulusan eksponensial pada waktu $t$,

$Y_{t}$ : data observasi pada waktu ke $t$,

$T_{t}$ : nilai pemulusan trend pada waktu $t$,

$\alpha$ : konstanta pemulusan untuk data asli $0<\alpha<1$,

$\beta$ : konstanta pemulusan untuk pola trend $0<\beta<1$,

$\gamma$ : konstanta pemulusan untuk pola musiman $0<\gamma<1$,

$S_{t}$ : nilai pemulusan musiman pada waktu $t$.

\subsection{Metode Seasonal ARIMA}

Model SARIMA merupakan model ARIMA yang mengandung unsur musiman. Secara umum bentuk model ARIMA musiman atau $\operatorname{SARIMA}(p, d, q)(P, D, Q)^{12}$ dapat ditulis :

$$
\Phi_{p}(B) \Phi_{p}^{*}\left(B^{S}\right)(1-B)^{d}\left(1-B^{S}\right)^{D} X_{t}=\theta_{q}(B) \theta_{q}^{*}\left(B^{S}\right) \epsilon_{t}
$$


dimana :

$$
\begin{aligned}
\Phi_{p} & : \text { parameter autoregressive }(\mathrm{AR}) \text { orde } p \\
\theta_{q} & : \text { parameter moving average }(\mathrm{MA}) \text { orde } q \\
\Phi_{p}{ }^{*}: & \text { parameter seasonal autoregressive (SAR) orde } P \\
\theta_{q}{ }^{*}\left(B^{S}\right) & : \text { parameter seasonal moving average (SMA) orde } Q \\
(1-B)^{d}: & \text { differencing non musiman orde } d \\
\left(1-B^{S}\right)^{D}: & \text { differencing musiman orde } D \\
s: & \text { panjang periode musiman, } \\
p, q: & \text { orde nonmusiman AR dan MA, } \\
P, Q: & \text { orde musiman AR (SAR) dan musiman MA (SMA). }
\end{aligned}
$$

Adapun langkah-langkah dalam peramalan dengan metode Seasonal ARIMA:

a. Identifikasi Data

Tahap pertama dalam identifikasi data time series yaitu membuat plot data aktual. Dari plot data time series tersebut dapat diselidiki kestasioneran data terhadap ragam dan nilai tengah. Data yang belum stasioner terhadap ragam dapat distasionerkan dengan melakukan Transformasi Box-Cox. Jika data belum stasioner terhadap nilai tengah maka dapat distasionerkan dengan melakukan differencing (pembedaan).

b. Identifikasi Model

Setelah data distasionerkan maka selanjutnya dilakukan identifikasi model, menentukan orde $\mathrm{p}, \mathrm{d}$, q. Orde $\mathrm{p}, \mathrm{d}, \mathrm{q}$ tersebut dapat diketahui dari korelogram fungsi autokorelasi (ACF) dan fungsi autokorelasi parsial (PACF).

c. Pendugaan Parameter

Pendugaan parameter model dilakukan dengan cara trial dan error dengan bantuan software minitab.

d. Diagnostik Model

Dalam menentukan model terbaik harus dipilih model yang memenuhi dua asumsi residual yaitu berdistribusi normal dan white noise.

\subsection{Perbandingan Metode Holt Winter dan Seasonal ARIMA}

Untuk menetukan model yang terbaik antara metode Holt Winter dan Seasonal ARIMA dilihat dari nilai $M A P E, M A D$ dan $M S D$ yang terkecil diantara kedua model tersebut.

\section{Pembahasan}

Pada Gambar 1 diberikan plot data perkembangan jumlah wisatawan mancanegara yang datang ke Indonesia periode Januari 2010 sampai dengan Desember 2014.

Pada Gambar 1 ditunjukkan bahwa data perkembangan wisatawan mancanegara yang datang ke Indonesia dipengaruhi pola trend dan pola musiman sekaligus, oleh karena itu kita menggunakan metode peramalan Holt Winter dan SARIMA untuk meramalkan perkembangan wisatawan mancanegara yang datang ke Indonesia. 


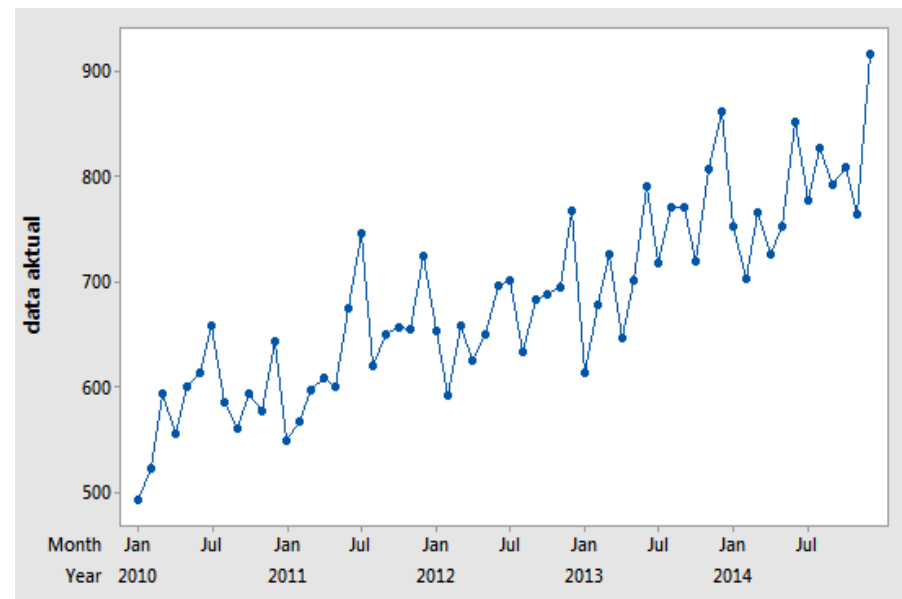

Gambar 1. Plot Data Aktual

a. Metode Holt Winter

\begin{tabular}{|c|l|c|c|c|}
\hline No & Konstansta Pemulusan & MAPE & MAD & MSD \\
\hline 1 & $\alpha=0.1 \beta=0.1 \gamma=0.1$ & 4.29 & 28.80 & 1193.37 \\
\hline 2 & $\alpha=0.1 \beta=0.1 \gamma=0.2$ & 4.33 & 29.15 & 1226.78 \\
\hline 3 & $\alpha=0.2 \beta=0.3 \gamma=0.1$ & 4.23 & 28.64 & 1201.46 \\
\hline 4 & $\alpha=0.2 \beta=0.1 \gamma=0.1$ & 3.97 & 26.84 & 1088.63 \\
\hline 5 & $\alpha=0.2 \beta=0.2 \gamma=0.2$ & 4.21 & 28.52 & 1188.40 \\
\hline 6 & $\alpha=0.3 \beta=0.2 \gamma=0.1$ & 4.06 & 27.49 & 1117.83 \\
\hline 7 & $\alpha=0.3 \beta=0.1 \gamma=0.2$ & 4.08 & 27.67 & 1106.45 \\
\hline 8 & $\alpha=0.4 \beta=0.1 \gamma=0.1$ & 3.97 & 27.01 & 1098.06 \\
\hline 9 & $\alpha=0.3 \beta=0.3 \gamma=0.1$ & 4.13 & 27.96 & 1156.39 \\
\hline
\end{tabular}

Tabel 1. Pendugaan konstanta pemulusan

Dengan bantuan software minitab kombinasi yang mengahasilkan nilai $M A P E, M S D$ serta $M A D$ yang terkecil yaitu pada kombinasi $\alpha, \beta$ dan $\gamma$ sebesar $0.2,0.1,0.1$

Pada Tabel 2 diberikan hasil peramalan perkembangan wisatawan mancanegara dengan metode Holt Winter.

b. Metode Seasonal ARIMA

Langkah pertama yang dilakukan pada tahap identifikasi data yaitu melihat kestasioneran data terhadap ragam dan nilai tengah. Ketidakstasioneran terhadap ragam dapat dilihat dari transformasi Box-Cox. Dari hasil analisis, plot data asli perkembangan wisatawan mancanegara yang datang ke Indonesia belum stasoner dalam ragam, sehingga perlu dilakukan transformasi $1 / \sqrt{X_{t}}$ terhadap data. Setelah data ditransformasikan, data sudah stasioner dalam ragam karena nilai lamda -0.5 menjadi 1 . Untuk menstasionerkan data terhadap rata- 


\begin{tabular}{|c|l|}
\hline Bulan & Ramalan \\
\hline Januari 2015 & 739.80 \\
\hline Februari 2015 & 739.73 \\
\hline Maret 2015 & 806.08 \\
\hline April 2015 & 762.81 \\
\hline Mei 2015 & 797.39 \\
\hline Juni 2015 & 875.19 \\
\hline Juli 2015 & 870.46 \\
\hline Agustus 2015 & 832.90 \\
\hline September 2015 & 838.06 \\
\hline Oktober 2015 & 842.40 \\
\hline November 2015 & 851.73 \\
\hline Desember 2015 & 954.33 \\
\hline
\end{tabular}

Tabel 2. Hasil Peramalan dengan Metode Holt Winter

rata dilakukan differencing terhadap hasil transformasi. Ketidakstasioneran terhadap rata-rata dapat diketahui dari Uji Augmented Dicky-Fuller.

Setelah data distasionerkan maka langkah selanjutnya dilakukan identifikasi model berdasarkan korelogram ACF dan PACF.

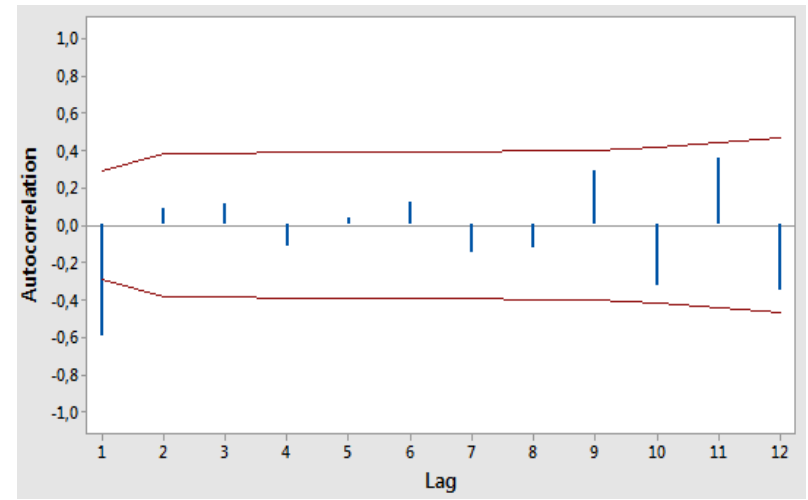

Gambar 2. Plot ACF setelah dilakukan differencing dan musiman

Berdasarkan Gambar 2 dan Gambar 3 dapat diduga model Seasonal ARIMA $(2,1,1)(2,1,1)^{12}$

Tahap selanjutnya adalah pendugaan dan pengujian parameter. Pada pendugaan para-meter dapat digunakan uji signifikan dan untuk pengujian parameter menggunakan uji white noise.

Tabel 3 menunjukkan bahwa model SARIMA $(2,1,0)(1,1,0)^{12}$, SARIMA $(2,1,0)(0,1,1)^{12}$, SARIMA $(0,1,1)(1,1,0)^{12}$ serta SARIMA $(0,1,1)(0,1,1)^{12}$ yang memenuhi signifikansi, residual berdistribusi normal dan white noise.

Metode yang paling baik digunakan adalah metode yang menghasil ni- 


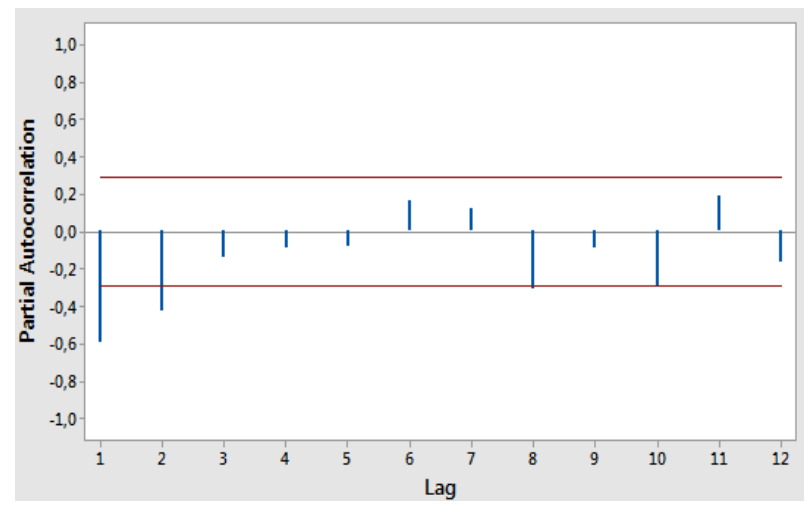

Gambar 3. Plot PACF setelah dilakukan differencing dan musiman

\begin{tabular}{|c|l|c|l|}
\hline Model & Uji Signifikansi Model & Uji White Noise & Uji Normal \\
\hline $\begin{array}{c}\text { SARIMA } \\
(1,0,0)(0,1,1)^{12}\end{array}$ & Signifikan & Tidak White Noise & Normal \\
\hline $\begin{array}{c}\text { SARIMA } \\
(1,1,0)(1,1,1)^{12}\end{array}$ & Tidak Signifikan & Tidak White Noise & Normal \\
\hline $\begin{array}{c}\text { SARIMA } \\
(2,1,0)(1,1,0)^{12}\end{array}$ & Signifikan & White Noise & Normal \\
\hline $\begin{array}{c}\text { SARIMA } \\
(2,1,0)(0,1,1)^{12}\end{array}$ & Signifikan & White Noise & Normal \\
\hline $\begin{array}{c}\text { SARIMA } \\
(0,1,1)(1,1,1)^{12}\end{array}$ & Tidak Signifikan & White Noise & Normal \\
\hline $\begin{array}{c}\text { SARIMA } \\
(2,1,0)(1,1,1)^{12}\end{array}$ & Tidak Signifikan & White Noise & Normal \\
\hline $\begin{array}{c}\text { SARIMA } \\
(0,1,1)(1,1,0)^{12}\end{array}$ & Signifikan & White Noise & Normal \\
\hline $\begin{array}{c}\text { SARIMA } \\
(0,1,1)(0,1,1)^{12}\end{array}$ & Signifikan & White Noise & Normal \\
\hline $\begin{array}{c}\text { SARIMA } \\
(1,1,1)(0,1,1)^{12}\end{array}$ & Tidak Signifikan & White Noise & Normal \\
\hline $\begin{array}{c}\text { SARIMA } \\
(1,1,0)(1,1,0)^{12}\end{array}$ & Signifikan & Tidak White Noise & Normal \\
\hline
\end{tabular}

Tabel 3. Ringkasan Uji Signifikan, Uji White Noise, serta Normalitas

lai MAPE, MAD serta MSD yang paling kecil yaitu pada model SARIMA $(0,1,1)(1,1,0)^{12}$ dengan persamaan sebagai berikut :

$$
\left[\left(1-\Phi_{1} B^{12}\right)(1-B)\left(1-B^{12}\right)\right] X_{t}=\left(1-\theta_{1} B\right) \epsilon_{t}
$$

Selanjutnya dilakukan peramalan dari model terbaik yang diperoleh dengan 


\begin{tabular}{|c|l|c|l|}
\hline Model & Nilai MAPE & Nilai MSD & Nilai MAD \\
\hline $\begin{array}{c}\text { SARIMA } \\
(2,1,0)(1,1,0)^{12}\end{array}$ & 3.49 & 1108.16 & 24.45 \\
\hline $\begin{array}{c}\text { SARIMA } \\
(2,1,0)(0,1,1)^{12}\end{array}$ & 3.60 & 1159.05 & 25.25 \\
\hline $\begin{array}{c}\text { SARIMA } \\
(0,1,1)(1,1,0)^{12}\end{array}$ & 3.22 & 1070.60 & 22.60 \\
\hline $\begin{array}{c}\text { SARIMA } \\
(0,1,1)(0,1,1)^{12}\end{array}$ & 3.50 & 1187.11 & 24.54 \\
\hline
\end{tabular}

Tabel 4. Tabel Nilai $M A P E, M A D$, dan $M S D$ dari model

persamaan sebagai berikut :

$$
X_{t+1}=X_{t}+0.4494\left(X_{t-11}-X_{t-12}\right)+0.5506\left(X_{t-23}-X_{t-24}\right)-1.006 \epsilon_{t}+\epsilon_{t+1}
$$

c. Perbandingan hasil peramalan Holt Winter dan SARIMA

\begin{tabular}{|c|l|c|l|}
\hline Metode & Nilai MAPE & Nilai MSD & Nilai MAD \\
\hline $\begin{array}{c}\text { Holt Winter Multiplikatif } \\
(0.2 ; 0.1 ; 0.1)\end{array}$ & 3.97 & 1088.63 & 26.84 \\
\hline $\begin{array}{c}\text { Seasonal ARIMA } \\
(0,1,1)(1,1,0)^{12}\end{array}$ & 3.22 & 1070.60 & 22.60 \\
\hline
\end{tabular}

Tabel 5. Perbandingan nilai MAPE, MAD serta MSD pada Metode Holt Winter dan SARIMA

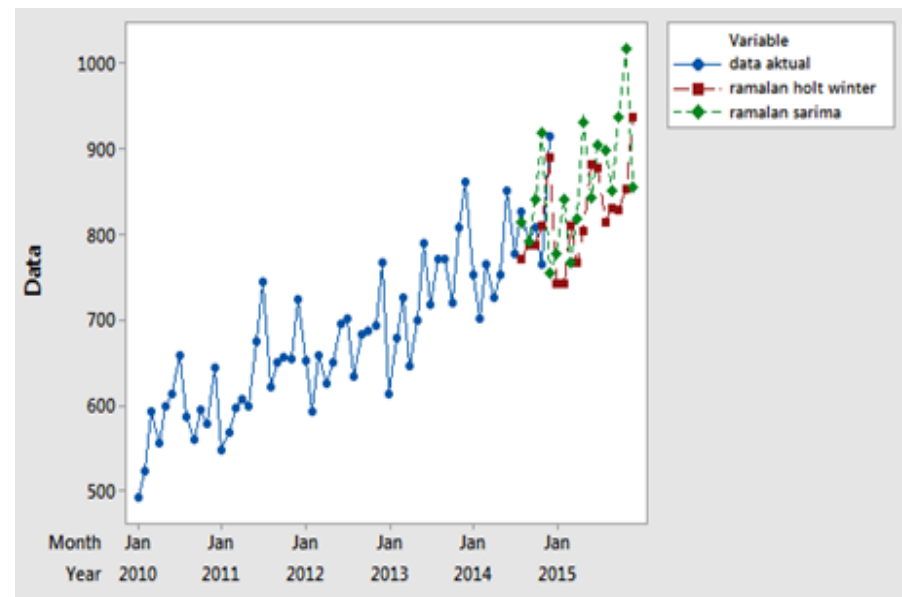

Gambar 4. Plot data asli dan hasil ramalan Holt Winter dan SARIMA

Berdasarkan Tabel 5 dapat diketahui bahwa metode Seasonal ARIMA lebih 
baik digunakan daripada metode Holt Winter karena menghasilkan nilai MAD, MSD serta MAPE yang lebih kecil.

\section{Kesimpulan}

Berdasarkan hasil pengolahan data dapat disimpulkan bahwa :

1. Model Holt Winter dari peramalan perkembangan wisatawan mancanegara yang datang ke Indonesia adalah model multiplikatif Holt Winter dengan persamaan sebagai berikut :

$$
\hat{Y}_{t+p}=\left(L_{t}+p T_{t}\right) S_{t-12+p}
$$

2. Model Seasonal ARIMA untuk meramalkan perkembangan wisatawan mancanegara yang datang ke Indonesia yaitu model SARIMA $(0,1,1)(1,1,0)^{12}$ dengan bentuk modelnya sebagai berikut :

$$
X_{t+1}=X_{t}+0.4494\left(X_{t-11}-X_{t-12}\right)+0.5506\left(X_{t-23}-X_{t-24}\right)-1.006 \epsilon_{t}+\epsilon_{t+1}
$$

3. Model terbaik untuk peramalan perkembangan wisatawan mancanegara yang datang ke Indonesia adalah model SARIMA $(0,1,1)(1,1,0)^{12}$, karena nilai $M A P E, M A D$ dan $M S D$ yang diperoleh lebih kecil daripada model Holt Winter .

\section{Ucapan Terima kasih}

Penulis mengucapkan terima kasih kepada Bapak Dr. Jenizon, Ibu Izzati Rahmi HG, M.Si dan Ibu Dr. Shelvi Ekariani yang telah memberikan masukan dan saran sehingga makalah ini dapat diselesaikan dengan baik.

\section{Daftar Pustaka}

[1] Badan Pusat Statistik. Konsep dan Definisi Statistik Kunjungan Wisatawan Mancanegara. http://www.bps.go.id , tanggal akses 11 April 2017

[2] Brockwell, P.J. dan Davis, R.A. 1996. Introduction to Time Series and Forecasting. Spinger Verlag, New York

[3] Hanke, J.E, Wichern, D.W. 2005. Business Forecasting Eight Edition. Pearson Prentice Hall, New Jersey.

[4] Kementerian Pariwisata. Statistik Wisatawan Mancanegara. http://www.kemenker.go.id, tanggal akses 10 April 2017.

[5] Makridakis, S., Wheelwright, S.C., McGee, V.E. 1999. Metode dan Aplikasi Peramalan Jilid 1 (Ir. Untung Sus Ardiyanto, M.Sc, Ir. Abdul Basith, M.Sc. Terjemahan) Edisi Kedua. Penerbit Erlangga, Jakarta

[6] Montgomery, D.C. 2007. Introduction to Time Series Analysis and Forecasting. John Wiley And Son, Inc, New York

[7] Wei, William W.S. 1990. Time Series Analysis: Univariate and Multivariate Methods. Addison Wesley, Canada 